ISSN $2230-8695$

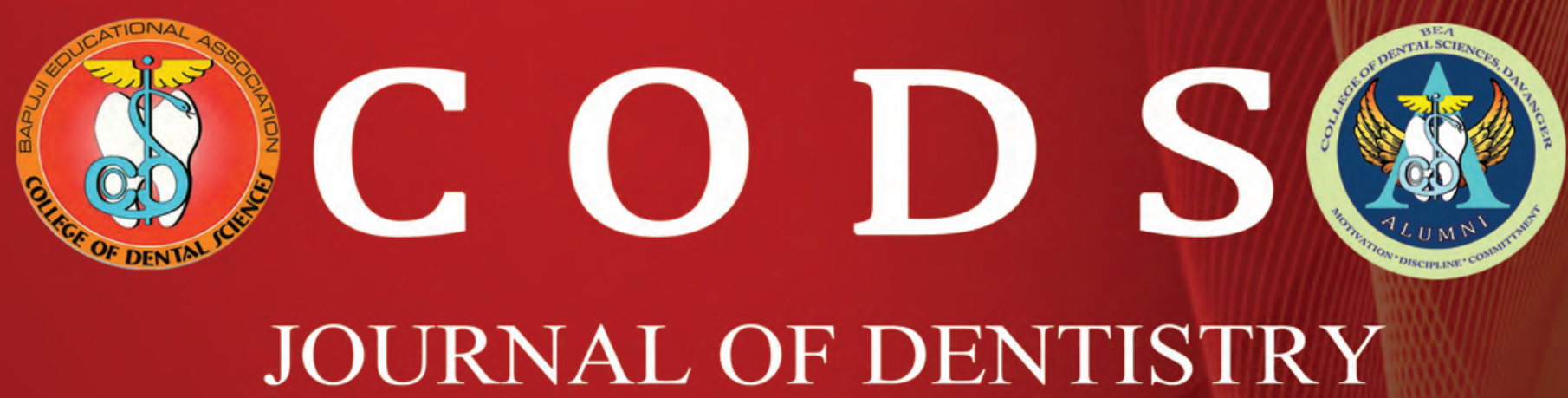

Official Publication of College of Dental Sciences Alumni Association, Davangere.

Volume $6 \cdot$ Issue $1 \bullet 2014$ 


\section{CODS Journal of Dentistry}

Official Publication of College of Dental Sciences Alumni Association, Davanagere

Volume 6, Issue 1, 2014

\section{CONTENTS}

Director's Message

V.V. Subba Reddy

President's Message

Vasundhara Shivanna

Secretary's Message

Praveen S. Basandi

Editorial

Nandini D.B

\section{Original Articles}

Effect of alcohol containing and alcohol free mouth rinses on microhardness of three esthetic restorative materials

Vasundhara Shivanna, Rucha Nilegaonkar

Prevalence and distribution of dental anomalies and fluorosis in a small cohort of

Indian school children and teenagers

Selvamani. M, Praveen S Basandi, Madhushankari G.S

\section{Review Articles}

Paperless dentistry - The future

Mala Ram Manohar, Gajendra Bhansali

Photo activated disinfection in restorative dentistry - A technical review

Deepak B.S, Mallikarjun Goud K, Nishanth P

An overview of occupational hazards in dental practice and preventive measures.

Poorya Naik .D.S, Chetan .S, Gopal Krishna.B.R, Naveen Shamnur

An overview on influences of estrogen and progesterone on periodontium 


\section{CODS Journal of Dentistry}

Official Publication of College of Dental Sciences Alumni Association, Davanagere

\section{Volume 6, Issue 1, 2014}

\section{CONTENTS}

\section{Review Articles}

Dental home - A new approach for child oral health care

Poornima P, Meghna Bajaj, Nagaveni N.B, Roopa K.B, V.V. Subba Reddy

Variants of inferior alveolar nerve block: A review

Anuradha M, Yashavanth Kumar D.S, Harsha .V. Babji, Rahul Seth

\section{Case Reports}

Ellis-van Creveld syndrome affecting siblings: A case report and review

Mamatha G.P, Manisha Jadhav , Rajeshwari G Annigeri, Poornima .P, V.V Subba Reddy

Integrated approach of ceramic and composite veneers in tetracycline

stained teeth: A case report.

Divya K.T, Satish .G

Fibrous dysplasia of right maxilla: A case report and review of literature

Guruprasad .L, Kavita Rao, Uma Devi H.S, Priya N.S

A case report of recurrent herpetic gingivostomatitis; with special reference to the role of cytology in diagnosis

Pramod K Jali, Nandini D.B, Mohan K.P, Madhushankari G.S

Eagle's syndrome with type III segmented styloid process : A case report.

Usha V. A, Mamatha G. P, Maria Priscilla David, 


\title{
Fibrous dysplasia of right maxilla: A case report and review of literature
}

\author{
Guruprasad L1, Kavita Rao², Uma Devi H S3, Priya N S
}

Post graduate student ${ }^{1}$, Professor $\& \mathrm{Head}^{2}$, Reader ${ }^{3,4}$

Dept. of Oral \& Maxillofacial Pathology, V.S. Dental College \& Hospital, Bangalore.

\begin{abstract}
:
Fibrous dysplasia is one of the most perplexing diseases of the fibro-osseous tissue. It is considered as a hamartomatous lesion of the bone and comprises $70 \%$ of the fibro osseous lesions. It is a disease of bone maturation and remodeling in which the normal medulla and cortices are replaced by disorganized fibrous woven bone. It is important to distinguish this lesion from other fibro osseous lesions mainly ossifying fibroma.

Pathologists usually confront difficulties in evaluating these fibro osseous lesions sharing similarities and differences with regard to clinical presentation, radiographic observation and microscopic picture. Accurate diagnosis of these lesions is of utmost importance to achieve optimal therapeutic goals.

A case of Fibrous dysplasia of maxilla with clinical, radiographic and routine histopathologic examination, along with special stains and blood chemistry is discussed here.
\end{abstract}

Keywords: Fibrous dysplasia, fibro osseous lesions, ossifying fibroma.

\section{Introduction:}

Jaw bones are the unique anatomical sites in the head and neck region which can harbor diverse pathological processes ranging from infection to neoplasm.

Though there is no accepted system for classifying bone disorders, fibro osseous lesions are a set of distinct bone pathologies. The most common fibro osseous lesions occurring in jaw bones are Fibrous dysplasia and Ossifying fibroma.

Fibrous dysplasia is a nonspecific hamartomatous skeletal developmental anomaly, characterized by slow progressive replacement of a localized area of bone by an abnormal proliferation of isomorphic fibrous tissue. ${ }^{1}$

\author{
Corresponding Author: \\ Dr. Guruprasad L. \\ PG student \\ Dept of Oral Pathology \\ V.S.Dental College \& Hospital \\ K.R.Road, VV Puram, \\ Bangalore. \\ E-mail: guru_201987@yahoo.com \\ Phone no: 9886020265
}

\section{Case report:}

A 13year old female patient presented with a complaint of diffuse swelling in the right middle third of the face (Fig 1). Swelling gradually increased in size over a period of 4 years, during which the patient was relatively asymptomatic.

Extraoral examination revealed diffuse solitary ovoid swelling present on the right middle third of the face extending superiorly from the right supraorbital ridge till $1 \mathrm{~cm}$ below ala tragus line inferiorly and medially from the inner canthus of the eye to $7 \mathrm{~cm}$ posterolaterally. Skin over the swelling was smooth and showed no colour change. The swelling was hard in consistency and non tender on palpation. Skin overlying the swelling showed no local rise in temperature and was movable (Fig 1).

Systemic examination revealed Café-au-lait spot on the back of the neck which was homogenous brown, oval in shape with irregular border.

Intra oral examination revealed a diffuse bony hard swelling measuring around $4 \times 1 \mathrm{~cm}$ in the right alveolar gingiva in relation to $13,14,15,16,17$ with obliteration of buccal vestibule (Fig 2). 
Provisional diagnosis of fibro osseous lesion like fibrous dysplasia with a differential diagnosis of ossifying fibroma was considered.

Occlusal radiograph revealed buccal cortical plate expansion with ground glass appearance (Fig 3). Orthopantamograph showed loss of lamina dura along with a ill defined radiopaque mass blending with adjacent normal bone in the right maxilla with a characteristic ground glass appearance in relation to 13,14,15,16,17 and right maxillary sinus (Fig 4). Posterior Anterior (PA) view of the skull showed haziness of maxillary sinus (Fig 5). Computed tomography revealed homogenous mass obliterating maxillary sinus and superior displacement of orbital floor and involvement of the palatal vault (Fig 6). Complete blood examination revealed an increase in alkaline phosphatase level 284 IU/L. (Normal level 20-120 IU/L).

Microscopic examination of incisional biopsy revealed fibrous stroma with trabeculae of immature bone arranged in Chinese letter pattern with no rimming of osteoblast (Fig7).

Special stains like Masson Trichrome and Picrosirus Red stain (PSR) was done to differentiate it from other fibro osseous lesions. Picrosirius red stained section under polarizing microscope showed randomly arranged collagen fibers (Fig 8). Masson Trichome stained section revealed bone which appeared greenish red indicating immature bone (Fig 9).

In correlation with clinical, radiographic and histopathological features, final diagnosis of Monostotic fibrous dysplasia of right maxilla was given.

Surgery was deferred till growth completion. Patient is on regular follow-up since then.

\section{Discussion:}

Fibro-osseous lesions of the jaws are a complex and diverse group of lesions characterized by a remarkably similar histological appearance with replacement of normal bone by a fibroblastic stroma containing varying amounts of mineralized substance, which may be bone and/or cementum- like in appearance.

Although the nomenclature and classification of these lesions is controversial, this generic term generally includes 3 broad categories of clinically and radiographically distinct entities: (1) fibrous dysplasia, (2) cemento-ossifying fibroma, and (3) cemento-osseous dysplasia. $^{2}$

Fibrous dysplasia was described by Lichtenstein in 1938 and by Lichtenstein and Jaffe in 1942. ${ }^{3}$

Fibrous dysplasia is postulated to occur as a result of a developmental failure in the remodeling of primitive bone to mature lamellar bone and a failure of the bone to realign in response to mechanical stress.
Failure of maturation leaves a mass of immature isolated trabeculae enmeshed in dysplastic fibrous tissue that are turning over constantly but never (or very slowly) completing the remodeling process. ${ }^{4}$

The etiology of fibrous dysplasia has been linked with a mutation in the GNAS1 gene that encodes the alpha subunit of the stimulatory $\mathrm{G}$ protein-coupled receptor, Gs $\alpha$, and is located at chromosome 20q13.2-13.3. The activating mutations occur post-zygotically, replacing the arginine residue amino acid with either a cysteine or a histidine amino acid. All cells that derive from the mutated cells manifest the dysplastic features. The clinical presentation varies, depending on the location of the mutation in the cell mass and the size of the cell mass during embryogenesis when the mutation occurs. ${ }^{1}$

The clinical presentation depends on the site, duration, extent and nature of the lesion.

These lesions present as firm painless swellings or deformities of the maxillofacial region. Lesions of the midface and periorbital region may be initially seen with nasal obstruction, sinus symptoms, headache, dental problems and possible visual disturbance.

Fibrous dysplasia appears in three distinctive clinical patterns:

- Single bone involvement (monostotic form), which is the most common presentation (70 percent of patients).

- Multiple bone involvement (Polyostotic form), a less common form (30 percent).

- McCune-Albright syndrome, a rare variant of polyostotic form with-café-au-lait skin pigmentation and endocrinologic abnormalities. ${ }^{5}$

The other syndrome associated with fibrous dysplasia is Mazabraud's syndrome which includes fibrous dysplasia and soft tissue myxomas.

Radiographically, Fibrous dysplasia shows radiolucent/radiopaque appearance, exhibits mottled radiopaque patterns, often described as resembling ground glass, orange peel, or fingerprints, with ill-defined borders blending into the normal adjacent bone.

Radionuclide bone scintigraphy is useful to demonstrate the extent of the disease. Actively forming lesions have greatly increased isotope uptake that corresponds closely to the radiographic extent of the lesion. The isotope scan shows increased uptake throughout life, but the uptake becomes less intense as the lesions mature. ${ }^{4}$

Computed tomography is the best technique for demonstrating the radiographic characteristics of fibrous dysplasia. The extent of the lesion is clearly visible on computed tomography, and the cortical boundary is depicted with more detail than is seen on radiographs or magnetic resonance images. 


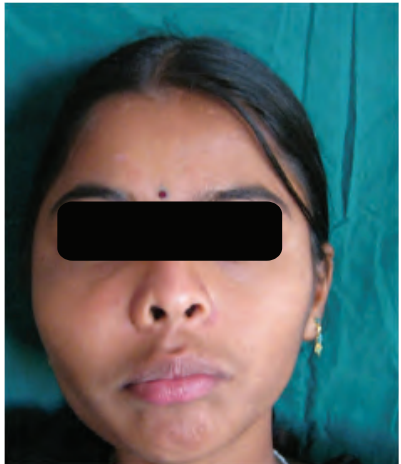

Fig 1: Solitary diffuse swelling in right middle third of the face.

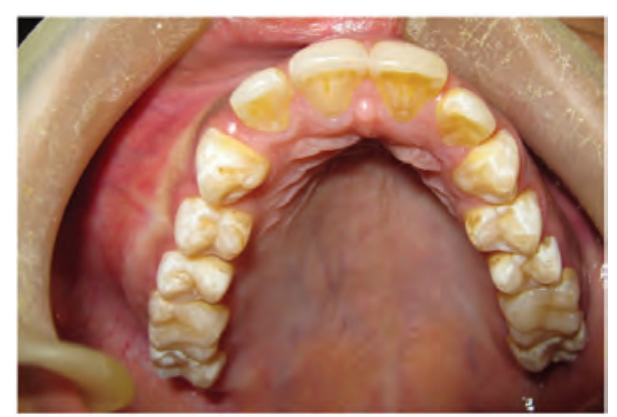

Fig 2: Intra oral swelling in the right alveolar gingiva measuring $4 \times 1 \mathrm{~cm}$ in relation to 14, 15, 16 and 17 with obliteration of buccal vestibule.

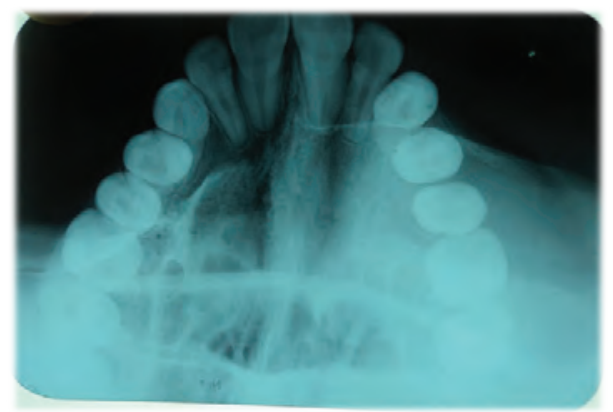

Fig 3: Occlusal radiograph showing expansion of buccal cortical plates on the right side.

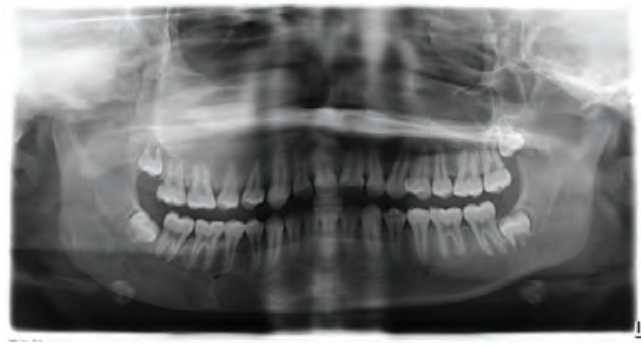

Fig 4: OPG showing radiopaque mass in right maxilla showing ground glass appearance.

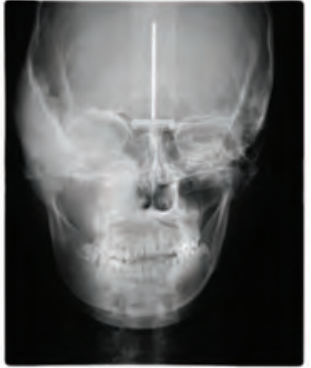

Fig 5: PA view of skull showing haziness in the right maxillary sinus.

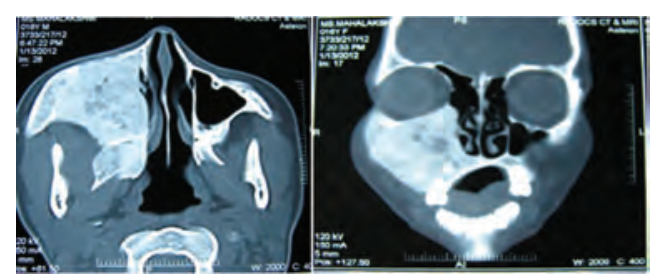

Fig 6: CT scan showing homogenous mass obliterating maxillary sinus with displacement of orbital floor \& palatal vault and expansion of buccal cortical plate.

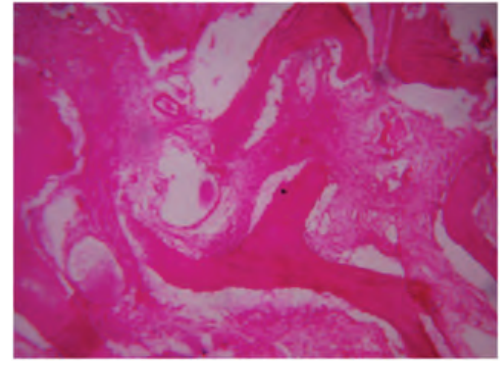

Fig 7: H\&E stained section showing fibrous stroma with trabaculae of immature bone arranged in Chinese letter pattern with absence of osteoblastic rimming.

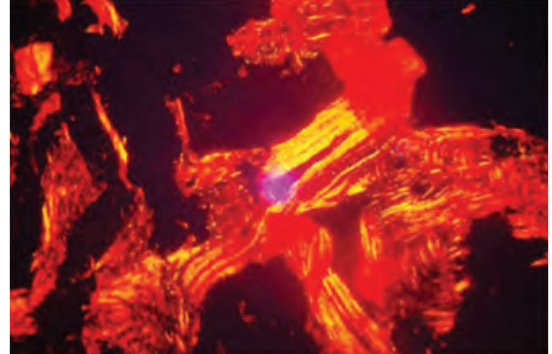

Fig 8: PSR stained section under polarizing microscope showing randomly arranged collagen fibers.

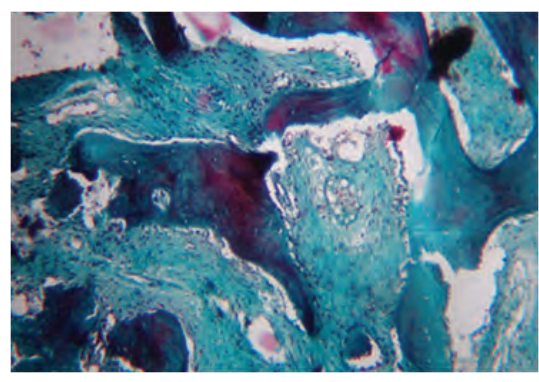

Fig 9: Masson trichome stained section showing green red immature bone. 
The thickness of the native cortex, amount of endosteal scalloping and periosteal bone reaction, and homogeneity of the poorly mineralized lesional tissue are demonstrated best with computed tomography imaging. ${ }^{4}$

Serum alkaline phosphatase, osteocalcin and urinary hydroxyproline are biochemical markers, the levels of which can be elevated in fibrous dysplasia. ${ }^{6}$

Gross specimen of fibrous dysplasia reveals a yellowish white tissue with a distinctive gritty feel, imparted by the small trabeculae of bone scattered throughout the lesion. ${ }^{7}$ Histologically fibrous dysplasia consists of irregularly shaped trabeculae of immature bone in a cellular loosely arranged fibrous stroma. The bony trabeculae are not connected to each other and show no osteoblastic rimming. The trabeculae often assume curvilinear shape which have been likened to "alphabet soup" or a "Chinese letter” appearance. ${ }^{2}$
Mesenchymal stroma surrounding the trabeculae is relatively hypocellular and is composed of spindle-shaped primitive mesenchymal cells that produce little or no collagen compared to ossifying fibroma. Numerous delicate capillaries are found throughout the lesion and, when injured, incite a giant-cell reactive process. $^{6}$

The histological features of fibrous dysplasia are site specific, in the cranial bones, they are pagetoid in nature, whereas in gnathic bones they are hypercellular, and in the axial/appendicular skeletons they have a Chinese character pattern, ${ }^{1}$ which is most often mistaken with ossifying fibroma and Paget's disease. Differentiating these lesions is necessary since treatment varies. (Table 1 \& 2)

Table 1: Differences between Fibrous dysplasia and ossifying fibroma ${ }^{8-10}$

\begin{tabular}{|c|c|c|}
\hline & Fibrous dysplasia & Ossifying fibroma \\
\hline Definition & $\begin{array}{l}\text { It is characterized by slow, progressive } \\
\text { replacement of a localized area of bone } \\
\text { by an abnormal proliferation of } \\
\text { isomorphic fibrous tissue intermixed } \\
\text { with poorly formed, haphazardly } \\
\text { arranged trabeculae of woven bone }\end{array}$ & $\begin{array}{l}\text { It is a well demarcated benign fibro osseous } \\
\text { tumor with capsule composed of } \\
\text { metaplastic bone, fibrous tissue and varying } \\
\text { amount of osteoid. }\end{array}$ \\
\hline Described by & Lichtenstein and Jaffe in 1942. & $\begin{array}{l}\text { Menzel in } 1872 \text { and later the term was } \\
\text { applied by Montgomery } 1927 \text {. }\end{array}$ \\
\hline Etiology & $\begin{array}{l}\text { Earlier it was considered due to } \\
\text { developmental failure in the remodeling } \\
\text { of primitive bone to mature lamellar } \\
\text { bone and a failure of the bone to realign } \\
\text { in response to mechanical stress } \\
\text { Now, it is said to be due to mutation in } \\
\text { the GNAS1 gene that encodes the alpha } \\
\text { subunit of the stimulatory G protein- } \\
\text { coupled receptor, Gs } \alpha \text {, and is located at } \\
\text { chromosome 20q13.2-13.3 }\end{array}$ & $\begin{array}{l}\text { Earlier there were various theories that } \\
\text { included trauma, a neoplastic process and } \\
\text { developmental defect. } \\
\text { Recent studies have shown that it can arise } \\
\text { due to Haploinsufficiency of the HRPT2 } \\
\text { gene, the gene that encodes parafibromin } \\
\text { protein. }^{9}\end{array}$ \\
\hline Types & $\begin{array}{l}\text { 1. Monostotic form } \\
\text { 2. Polyostotic form } \\
\text { 3. Mc Cune Albright syndrome }\end{array}$ & 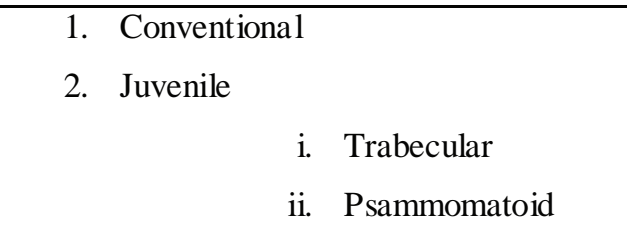 \\
\hline
\end{tabular}




\begin{tabular}{|c|c|c|}
\hline $\begin{array}{l}\text { Clinical } \\
\text { fe atures } \\
\text { Age } \\
\text { Sex } \\
\text { Site }\end{array}$ & $\begin{array}{l}\qquad 1^{\text {st }} \& 2^{\text {nd }} \text { decade } \\
\text { Male and female are equally affected } \\
\text { Maxilla (anterior region) }\end{array}$ & $\begin{array}{l}\qquad 3^{\text {rd }} \& 4^{\text {th }} \text { decade } \\
\text { Female predilection is seen } \\
\text { Mandible (posterior region) }\end{array}$ \\
\hline Presentation & $\begin{array}{l}\text { 1. Multiple bones involved } \\
\text { 2. Jaw expansion is seen } \\
\text { (enlongated, fusiform) } \\
\text { 3. Tooth displacement or root } \\
\text { resorption is rare } \\
\text { 4. Growth is longitudinal } \\
\text { 5. Café-au-lait spots on skin are } \\
\text { seen } \\
\text { 6. Endocrine involvement is seen }\end{array}$ & $\begin{array}{l}\text { 1. Single bone involved } \\
\text { 2. Jaw expansion is seen (nodular, } \\
\text { dome shaped) } \\
\text { 3. Tooth displacement or root } \\
\text { resorption is noted } \\
\text { 4. Growth is spherical } \\
\text { 5. Pigmentations are absent } \\
\text { 6. Endocrine involvement is absent }\end{array}$ \\
\hline $\begin{array}{l}\text { Radiographic } \\
\text { features }\end{array}$ & $\begin{array}{l}\text { Poorly defined borders blending with } \\
\text { normal adjacent bone showing mixed } \\
\text { radiolucent and radiopaque areas. } \\
\text { Characteristic ground glass appearance. }\end{array}$ & $\begin{array}{l}\text { Well defined borders with mixed } \\
\text { radiolucent and radiopaque areas. }\end{array}$ \\
\hline Macroscopy & $\begin{array}{l}\text { Lesional tissue show yellowish white } \\
\text { with scattered bony spicules. }\end{array}$ & Lesional tissue is well circumscribed. \\
\hline
\end{tabular}

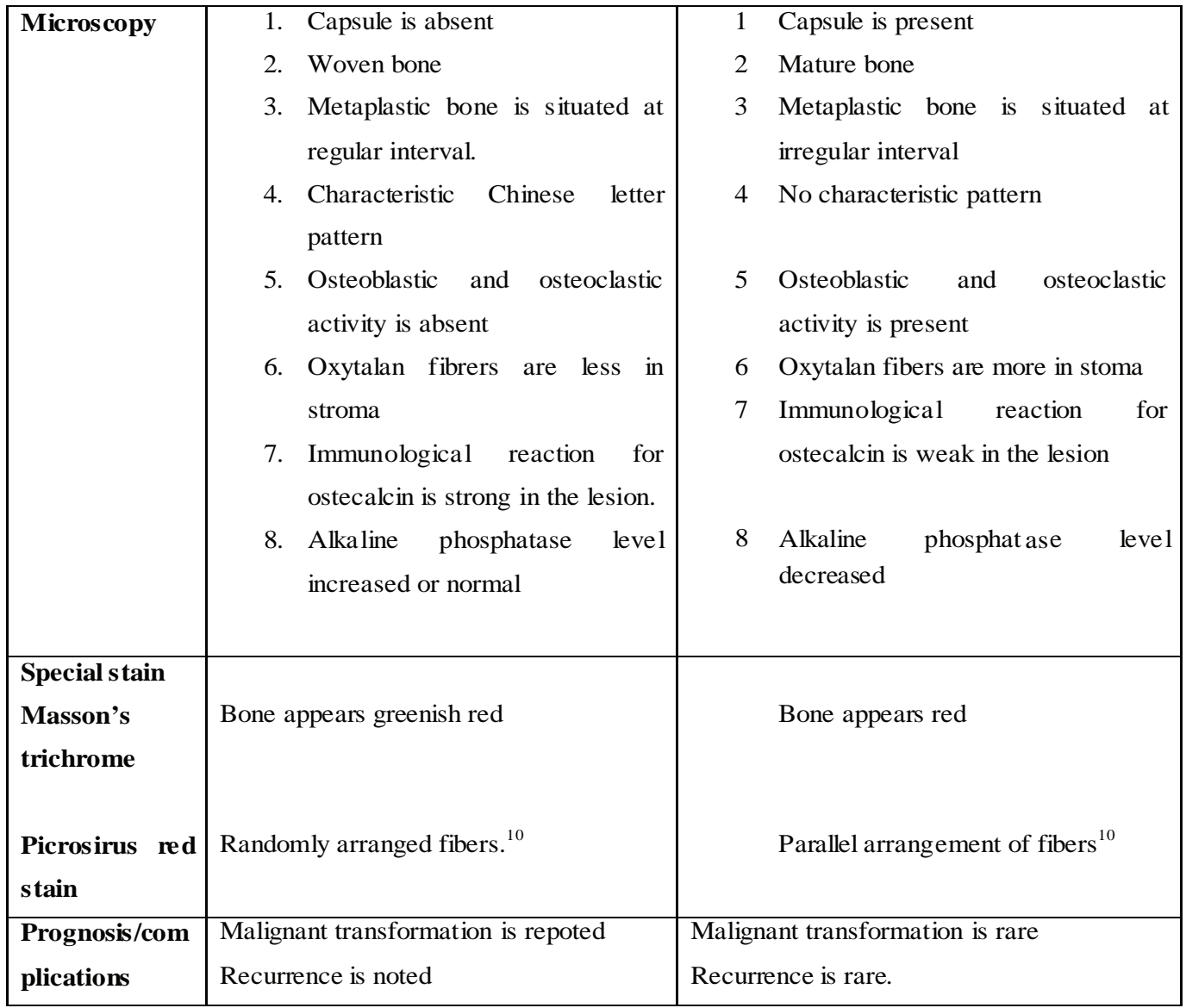


Table 2: Differences between Fibrous dysplasia and Paget's disease.

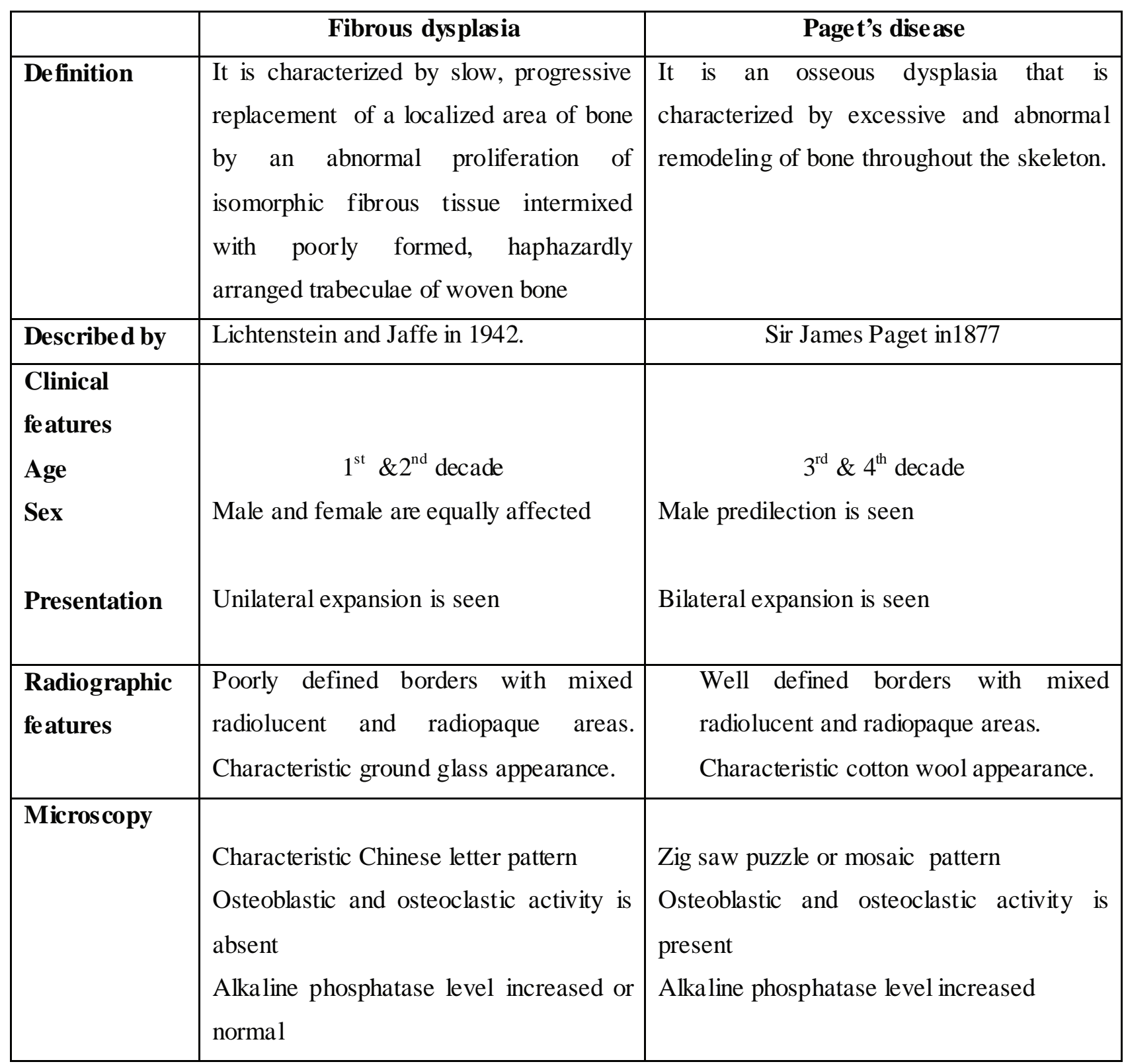




\section{Prognosis:}

Malignant transformation of fibrous dysplasia occurs very infrequently, with reported prevalence ranging from $0.4 \%$ to $4 \%$, most commonly into osteosarcoma, fibrosarcoma, and chondrosarcoma. ${ }^{11.12}$

Management: Monostotic lesions frequently are encountered incidentally and require clinical observation. Confirmatory biopsy is indicated if the radiographic findings are not characteristic of fibrous dysplasia. Treatment is usually deferred till puberty since the lesion is self limiting. Conservative treatment like bone recontouring and alveoplasty are advised in case of disfigurement. Bisphosphonates have been shown to offer pain relief and improve skeletal strength in appropriately selected patients with either polyostotic or monostotic fibrous dysplasia. Occasionally, operative treatment is needed to correct deformity or to prevent or stabilize a pathologic or fatigue fracture.

Conclusion: Fibro- osseous lesions exhibit a variety of clinical behavior, but share common microscopic features consisting of a benign connective tissue matrix and new bone formation. Overlapping histologic features of entities within this group and atypical features of individual lesions often make definitive diagnosis difficult. Therefore clinical features, imaging characteristics and histopathological findings should be correlated to reach a correct diagnosis and enable effective treatment planning.

\section{References:}

1. Sumathy C, Seethalakshmi C, Saraswathy Gopal K. Fibrous Dysplasia of the Maxilla - Report of two cases with review. Indian Journal of Multidisciplinary Dentistry 2011;1:100-10.

2. Neville BW, Damm DD, Allen CM, Bouquot JE. Textbook of Oral and Maxillofacial Pathology.3rd ed. Philadelphia Pennyslavania: W B Saunders Elesvier publishers; 2009.

3. Chen YR, Chang CN, Tan YC. Craniofacial fibrous dysplasia: an update. Chang Gung Med J 2006;29:543-9.

4. DiCaprio MR, Enneking WF. Fibrous dysplasia Pathophysiology, Evaluation, and treatment. J Bone Joint Surg Am 2005; 87: 1848-64.

5. Pervin KI, Husnu E, Ali D, Sezer K. Fibrous dysplasia of the cranial bones: A case report and review of the literature. Yale Journal of Biology and Medicine 2005; 78:139-143.
6.Harsh Mohan, Preeti Mittal, Irneet Mundi, Sudhir K. Fibrous dysplasia of bone: A clinicopathologic review. Pathology and Laboratory Medicine International 2011;3:31-42.

7.Suresh M, SriHari V, Veena K, Khurshida B, Shanu Etaiah, Vinay M, Kashyap. Craniofacial fibrous dysplasia: Surgery \& literature review. Ann Maxillofacial sur 2013;3:66-71.

8.Gnepp DR. Diagnostic surgical pathology of the head \& neck. 2nd Ed. USA: W.B.Saunders Company; 2001.

9.Satoru Toyosawa, Michiko Yuki, Mitsunobu Kishino, Yuzo Ogawa, Takafumi Ueda, Shumei Murakami et al. Ossifying fibroma Vs fibrous dysplasia of the jaw: molecular and immunological characterization. Modern Pathology 2007; 20: 389-96

10.Anubha G, Nirmala NR, Raghu AR. Fibrous Dysplasia and Ossifying Fibroma - An advent in their diagnosis. J Clin Exp Dent 2011;3:297-302.

11.Carrie Y. Inwards. Low-Grade Central Osteosarcoma versus Fibrous Dysplasia. Pathology Case Reviews 2001;6(1):22-27.

12.Pietro R, Jeffrey R. Bond, K. Krishnan U. Malignancies in Fibrous Dysplasia. Cancer 1994; 73:1411-24.

How to cite this article:

Guruprasad L, Kavita R, UmaDevi HS, Priya NS. Fibrous dysplasia of right maxilla: A case report and review of literature. CODS J Dent 2014;6;49-55

Source of support: Nil. Conflict of interest: None Declared. 